\title{
Insulin Neuropathy: Rare Adverse Effect of Insulin Therapy
}

Ergun B

\begin{abstract}
$\underline{\text { Abstract: }}$
Insulin neuropathy is a rare adverse effect of insulin therapy in patients with long-term uncontrolled hyperglycemia. Neuropathic pain appears after the correction of blood glucose level. A 34 years old woman with severe neuropathic pain appeared immediately after the beginning of insulin therapy and could not be responded to neuropathic pain relief drugs is reported. Insulintreatment may cause severe neuropathic pain that cannot be result with neuropathic pain relief drugs.
\end{abstract}

Keywords: insulin; adverse effect; neuropathy

Bangladesh Journal of Medical Science Vol. 15 No. 02 April'16. Page : 303-304

\section{Introduction}

Insulin treatment is preferable for the rapid correction of blood glucose level in diabetic patients with long-term hyperglycemia (1). Painful neuropathy development has been described as a rare and severe complication of insulin therapy. Only a few acute painful neuropathy case reports have been published so far. Although the underlying mechanism is unclear, axonal damage development related to hypoglycemia is thought to be the possible mechanism (2). Insulin-induced neuropathy mimics diabetic peripheral neuropathy which is a more common complication, to distinguish between these adverse events is difficult. In this paper, a case of insulin-induced neuropathy is reported.

\section{Case report}

A 34 years old woman with long-term hyperglycemia because she had refused pharmacotherapy for 2 years, has begun to be treated with insulin aspart + insulin aspartprotamincombination (70IU/day) and metformin $1000 \mathrm{mg}$ (2x1/day) for rapid glycemic control. Few weeks after the beginning of insulin therapy, blood glucose level has attained to normal range, but severe back pain complaint has developed. Numerous analgesics and myorelaxants such asflurbiprofen, thiocolchicoside, ketoprofen andnimesulid in oral and topical forms have been prescribed by the family physician for pain relief. However, the widespread back pain complaint has worsened in time. Insulin therapyhas been regulated by an internal specialist as insulin detemir(2x50 IU/ daily) and insulin aspart(3x30 IU/day). But severe back pain could not resolve after this regulation. Thereupon, the patient has been directed to an endocrinologist and alpha lipoicacid (600 mg, 1x 1 daily), gabapentin (600 mg 2x1daily), metformin (1000mg, 2x1 daily) and glyclaside (30 mg, 1x2 daily)have been added to her pharmacotherapy with diabetic peripheral neuropathic pain diagnosis.

However, severe back pain complaint continued in spite of alpha lipoic acid and gabapentin treatment. The pain was so severe that, patient could not sleep lie on back. She was recommended to use topical lidocainepomade for desensitization. But, this could not be enough to lessen the pain. Later, pioglitazone $\mathrm{HCl}(30 \mathrm{mg}, 1 \mathrm{x} 1$ daily) was added to her diabetes therapy by an internal specialist and her insulin treatment has been changed to insulin lispro + insulin lisproprotamin (3x20 IU daily) by anendocrinologist. Two months later sitagliptin phosphate monohydrate $(100 \mathrm{mg}, 1 \mathrm{x} 1$ daily) has been added her diabetes therapy and pregabalin (300 mg, 2x1 daily) has been started for neuropathic pain relief.Unfortunately sufficient pain relief could not be obtained with pregabalin. In this instance the condition of the patient has been consulted withphysicians. They have been informed about possible insulin neuropathy occurrence and recommended to stop insulin treatment. Few days after insulin therapy cessation, the pain has been resolved. Two months later blood glucose level has risen and insulin treatment has been started again.

1. Bulent Ergun, Anadolu University, Faculty of Pharmacy, Department of Pharmaceutical Toxicology Eskisehir, Turkey

Corresponds to: Bulent Ergun,Anadolu University, Faculty of Pharmacy, Department of Pharmaceutical Toxicology Eskişehir, Turkey. E-mail: silgin@anadolu.edu.tr 
However, severe pain complain has appeared again immediately after the start of insulin treatment. Therefore, insulin treatment has been completely stopped. Her pharmacotherapy has been regulated with oral antidiabetics including metformin, sitagliptin monohydrate phosphate and glyclaside. Her pain has completely resolved and therapy compliance has become better. Although blood glucose level cannot be attained to normal range with oral antidiabetics, the patient feels healthier and take her drugs ambitious.

\section{Discussion}

Neuropathic pain is a common complicationof diabetes. It is generally developedas a result of long-term uncontrolled hyperglycemia.However, insulin treatment related neuropathic pain, generally recognized after rapid blood glucose level correction in patients with long-term hyperglycemia, has been described in rare cases(2-5).

In present case, it has been demonstrated that insulin treatment related pain may be widespread and very severe that can reduce the life quality of the patient.It has also been shown that whilediabetic neuropathic pain can be well tolerated with gabapentin, alpha lipoicacid or pregabalin treatment, pain due to insulin neuropathy cannot be resolved with these drugs. Since diabetic neuropathic pain is more common and the symptoms are similar, insulin neuropathy cannot be diagnosed and therefore patients cannot be treated correctly.

Cessation of the insulin treatment for few weeks seems to be the best way for the exact diagnosis of insulin neuropathy. Pain is generally resolved few days after insulin treatment stop.In the patients who developed insulin neuropathy, blood glucose level must be controlled using oral antidiabetics. In patients receiving insulin,possible insulin neuropathydevelopment must always be kept in mind, especially in case of severe pain complaint started immediately after the beginning of insulin treatment.

\section{$\underline{\text { References }}$}

1. Greene RJ and HarrisND. Pathology and therapeutics for pharmacists: A basisclinical pharmacy practice. Second Edition. Pharmaceutical Press, London; 2000;546-559.

2. Dabby R, Sadeh M, Lampl Y, Gilad R and Watemberg N. Acute painful neuropathy by rapid correction of serum glucose levels in diabetic patients. Biomedicine and Pharmacotherapy. 2009;63:707-709.

3. Rothacker KM and Kaye J. Insulin oedema and treatmentinduced neuropathy in a 20 -year old patient with type 1

diabetes commenced on an insulin pump. Diabet Med. 2014;31:c6 - c10.

4.Gibbons $\mathrm{CH}$ and Freeman R. Treatment induced diabetic neuropathy - a reversible painful autonomic neuropathy. Ann Neurol. 2010;67(4):534-541.

5. Wilson JL, Sokol DK, Smith LH, Snook RJ, Waguespack SG andKincald JC. Acute painful neuropathy (Insulin Neuritis) in a boy following rapid glycemic control for type 1 diabetes mellitus. J Child Neurol. 2003;18i:365. 